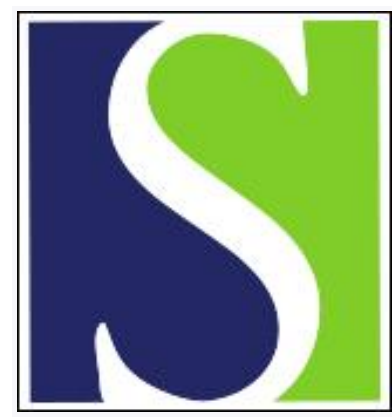

Scand J Work Environ Health 2019;45(2):134-145

https://doi.org/10.5271/sjweh.3777

Published online: 18 Oct 2018, Issue date: 01 Mar 2019

Organizational change and employee mental health: A prospective multilevel study of the associations between organizational changes and clinically relevant mental distress by Fløvik L, Knardahl S, Christensen JO

The current paper elucidates how various types of separate and repeated organizational changes in the workplace affect employee mental health, long-term. Results highlight the need to pay attention to employee mental health during both discrete and repeated, large and small-scale organizational change.

Affiliation: Department of Work Psychology and Physiology, National Institute of Occupational Health, PO Box 8149 Dep, N-0033 Oslo, Norway. lise.flovik@stami.no

Refers to the following texts of the Journal: 2017;43(3):234-240 2006;32(6):443-462

The following article refers to this text: 2020;46(4):392-401

Key terms: absenteeism; employee mental health; mental distress; mental health; multilevel analysis; occupational health; occupational health; organization; organizational change; presenteeism; productivity; prospective multilevel study; prospective study; psychosocial; sick leave; work environment

This article in PubMed: www.ncbi.nlm.nih.gov/pubmed/30334062

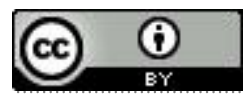




\title{
Organizational change and employee mental health: A prospective multilevel study of the associations between organizational changes and clinically relevant mental distress
}

\author{
By Lise Fløvik, Cand.psychol, ${ }^{1}$ Stein Knardahl, PhD, ${ }^{1}$ Jan Olav Christensen, PhD ${ }^{1}$
}

\begin{abstract}
Fløvik L, Knardahl S, Christensen J0. Organizational change and employee mental health: A prospective multilevel study of the associations between organizational changes and clinically relevant mental distress. Scand J Work Environ Health. 2019;45(2):134-145. doi:10.5271/sjweh.3777
\end{abstract}

\begin{abstract}
Objective The aim of the present paper was to elucidate the relationship between exposure to separate, multiple or repeated organizational change at both individual- and work-unit level and subsequent clinically relevant mental distress amongst employees two years after change had taken place.
\end{abstract}

\begin{abstract}
Methods A full panel, prospective design was utilized. Data were collected at two time-points two years apart, by self-administered, online questionnaires. Organizational change was measured by six items pertaining to separate types of change. Mental distress was measured using HSCL-10, with cut-off set to $\geq 1.85$ to identify clinically relevant distress. Baseline sample consisted of 7985 respondents, of whom 5297 participated at follow-up. A multilevel analytic strategy was chosen as data were nested within work-units. Effects associated with exposure to organizational change at both individual- and work-unit level were estimated.
\end{abstract}

Results Separate change: At the individual level, company reorganization [odds ratio (OR) 1.29, 95\% confidence interval (CI) 1.01-1.65], downsizing (1.51,95\% CI 1.12-2.03) and layoffs (OR 1.46, 95\% CI 1.01-2.12) were prospectively associated with mental distress. At work-unit level, company reorganization (OR 1.46, 95\% CI 1.04-2.04) was associated with mental distress, but the statistically significant association diminished when adjusting for the work factors job control, job demands and support. Multiple changes: At the individual level, exposure to multiple organizational changes at baseline were associated with mental distress at follow-up (OR $1.75,95 \%$ CI 1.28-2.38). Repeated change: At the individual level, exposure to repeated organizational change was associated with mental distress at follow-up (OR 1.84, 95\% CI 1.29-2.63).

Conclusions Exposure to organizational changes at the individual level indicated an elevated risk of subsequent clinically relevant mental distress following both separate, multiple and repeated organizational changes. These associations were also present at work-unit level, but diminished when adjusting for certain work factors, indicating a possible mediating effect.

Key terms absenteeism; multilevel analysis; occupational health; organization; presenteeism; prospective study; productivity; psychosocial; sick leave; work environment.

Organizational change is a hallmark of modern work life and widespread throughout all industries (1) but has repeatedly been linked to various mental and somatic health complaints $(2-8)$, sick leave $(3,4,9)$, and disability $(10,11)$. Although the rate of organizational change is increasing in both the private and public sectors (1), and continuous change is seemingly commonplace, prior studies have primarily focused on health effects following discrete organizational change events (12). Less attention has been devoted to the effects of repeated organizational change $(13,14)$ or multiple organizational changes occurring simultaneously $(13,15)$. Fur- thermore, extensive organizational change often affects the whole organization, including its departments, workunits and the individual worker. The majority of prior studies have focused on the effects of exposure at the individual level, not explicitly taking into account the multilevel aspect of extensive organizational changes. The objective of the present study was to elucidate the effects of exposure to various types and patterns of organizational change at both the individual level and work-unit level on employee mental distress. A large and diverse sample of Norwegian employees was studied to determine the prospective associations of exposure to

1 National Institute of Occupational Health, Department of Work Psychology and Physiology, Oslo, Norway.

Correspondence to Lise Fløvik, Department of Work Psychology and Physiology, National Institute of Occupational Health, PO Box 8149 Dep, N-0033 Oslo, Norway. [E-mail: lise.flovik@stami.no] 
various distinctive types and patterns of organizational change with subsequent clinically relevant mental distress. The effects of both separate, co-occurring, and repeated organizational change were examined.

Prior research has primarily focused on health effects following discrete, large-scale, organizationwide changes, such as company restructuring, outsourcing and downsizing $(12,16)$. Such changes have been associated with detrimental health effects $(3,17)$, sick leave $(3,4)$, work disability pension (18), early retirement (19), and mortality also among those who kept their jobs after the downsizing (4). Additionally, some studies have reported that the extent of downsizing (ie, the number of employees laid off), as well as prolonged and repeated organization-wide changes to be related to sick leave and emotional exhaustion $(17,20,21)$.

Mental illness is one of the main contributors to the global burden of disease and cause of work disability (22). It is also one of the most costly medical conditions $(23,24)$ and associated with a heavy economic burden for both the affected individual (25) and society $(24,26,27)$. Amongst the diagnosis constituting mental illness, depression is the most costly in total (28), with the indirect costs accounting for over half of total costs (23) and includes lower performance and productivity while at work (presenteeism) (29-31), sick leave compensation (31), disability claims (32) and tax-based production loss (23). Due to the widespreadness of both organizational change and mental distress in contemporary work life, clarifying the link between the two is an urgent matter likely to have a considerable impact on public economy and -health and company sustainability.

Most studies pertaining to the effects of organizational change on mental distress have focused on the individuals' response to change, often not taking into account the context in which change takes place. It is possible that mental distress is influenced both by the individual experience of exposure to change and the shared experience of change in the context in which the individual is embedded (eg, the work unit). Identification of work-related predecessors at both individual- and group level is essential in order to comprehensively elucidate the potentially detrimental effects of organizational change and furthermore to develop targeted interventions in order to prevent such effects. Moreover, measures of change at the group level may reflect how widespread change is within that specific group and clarify the extent to which employees share the perception of change taking place. Finally, group-level constructs should diminish the impact of specific characteristics of individual employees, which may bias estimates if, for instance, individuals that are more concerned about the prospect of change may over-report the occurrence of it.

The mechanisms regarding how exposure to different types and frequencies of organizational change affect employee health are complex and still pending (12). However, to posit potential pathways between organizational change and employee mental health one could draw upon empirically supported theoretical frameworks. One widely applied framework in occupational health psychology is the job demands-control-support model $(33,34)$, which points to factors in the work environment that may influence employee health. A potential pathway between organizational change and mental distress could be via the effect organizational change has on these factors. For instance, organizational change may require considerable individual and organizational effort to adapt, while existing job demands may remain unchanged or increased, which in total may imply a considerable net increase in job demands. However, organizational changes may also have a more direct effect on employee health, apart from the possible indirect effect on employee health via the work environment. For instance, organizational change may represent and induce job uncertainty and lowered predictability, caused by the change content or in what way or context change is implemented, and may be perceived intrinsically as a threat, causing distress and illness $(35,36)$.

In sum, there are several potential pathways between exposure to organizational changes and mental distress. The scope of the present study was to examine the total effect of various distinct types and patterns of organizational change on mental distress as well as the direct effect, controlled for central dimensions of the psychosocial work environment known to be associated with employee health, namely job demands, job control, and social support.

\section{Method}

\section{Population}

The study was a part of the project "The New Workplace: Work, Health and Participation in Working Life", initiated and carried out by the Norwegian National Institute of Occupational Health (NIOH) The study had a full panel design, with two waves of data collected with a two-year interval. Data were collected using a comprehensive online questionnaire covering a wide range of topics, eg, work environment and -organization, somatic and mental health, work ability and background information. All variables were measured at both measurement occasions. Baseline data were collected between 2004 and 2013, with follow-up collected two years after the time of baseline measurement.

The organizations participating in the study contacted the National Institute of Occupational Health in response to information about the project disseminated 
through the NIOH's home page or due to a more general wish to conduct a work environment survey. All current employees were invited to participate, including managers. In total 66 organizations located in Norway, including private and public enterprises and public administrations, took part in the study. A wide variety of sectors and types of organizations were represented, eg, municipalities, health care, finance, insurance, education and non-profit organizations.

A total of 15465 respondents were invited to participate at baseline. In total, 7985 respondents were included in the baseline sample, while 5297 respondents were included in the prospective sample. Mean age at baseline was 44.34 years [standard deviation (SD) 10.6]. Non-response was associated with working in professions requiring formal education of $<12$ years. Women were less likely to be non-respondents. See table 1 for details.

Dropout was defined as not having completed the outcome measure (HSCL-10) at follow-up. Attrition analysis showed that $33.5 \%(\mathrm{~N}=2688)$ of the respondents participating at baseline did not respond at follow-up.

Table 1. Characteristics of baseline sample and prospective sample. Inclusion criteria was completion of HSCL-10 and all organizationwide and individual-specific change items.

\begin{tabular}{|c|c|c|c|c|c|c|}
\hline & \multicolumn{2}{|c|}{ Invited subjects } & \multicolumn{2}{|c|}{ Baseline sample } & \multicolumn{2}{|c|}{ Prospective sample } \\
\hline & $\mathrm{N}$ & $\%$ & $\mathrm{~N}$ & $\%$ & $\mathrm{~N}$ & $\%$ \\
\hline \multicolumn{7}{|l|}{ Sex } \\
\hline Female & 8467 & 54.7 & 4218 & 52.8 & 2842 & 53.2 \\
\hline Male & 6998 & 45.3 & 3767 & 47.2 & 2455 & 46.8 \\
\hline Total & 15465 & & 7985 & & 5297 & \\
\hline Missing & & & 7480 & & 10387 & \\
\hline \multicolumn{7}{|l|}{ Age } \\
\hline $29-39$ & & & 678 & 8.5 & 415 & 7.8 \\
\hline$>39-49$ & & & 2090 & 26.2 & 1378 & 26.0 \\
\hline$>49-59$ & & & 2645 & 33.2 & 1797 & 33.9 \\
\hline$>59$ & & & 2563 & 32.1 & 1707 & 32.2 \\
\hline Total a & & & 7985 & 100 & 5297 & 100 \\
\hline \multicolumn{7}{|l|}{ Skill level (years) } \\
\hline$>10-12$ & & & 3862 & 48.3 & 2591 & 49.0 \\
\hline $13-15$ & & & 2000 & 25,0 & 1216 & 23.0 \\
\hline$>15$ & & & 2123 & 26,6 & 1490 & 28.1 \\
\hline \multicolumn{7}{|l|}{ HSCL-10 } \\
\hline Above cut-off & & & 974 & 12.2 & 615 & 11.6 \\
\hline Below cut-off & & & 7011 & 87.8 & 4682 & 88.4 \\
\hline \multicolumn{7}{|l|}{ Workplace } \\
\hline Public sector & 11792 & 76.2 & 1661 & 20.2 & 1095 & 20.7 \\
\hline Private sector & 3673 & 23.8 & 6324 & 79.2 & 4202 & 79.3 \\
\hline \multicolumn{7}{|l|}{$\begin{array}{l}\text { Organizational } \\
\text { change }\end{array}$} \\
\hline Reorganizing & & & 5350 & 55.0 & 4429 & 28.6 \\
\hline Downsizing & & & 2406 & 15.6 & 1943 & 12.6 \\
\hline Layoff & & & 911 & 9.4 & 1079 & 7.02 \\
\hline Partial closure & & & 1236 & 8.2 & 1056 & 6.8 \\
\hline $\begin{array}{l}\text { Partial } \\
\text { outsourcing }\end{array}$ & & & 776 & 5.0 & 992 & 6.4 \\
\hline $\begin{array}{l}\text { Change of } \\
\text { ownership/ } \\
\text { aquisition }\end{array}$ & & & 643 & 4.2 & 585 & 3.8 \\
\hline
\end{tabular}

Drop-out was associated with experiencing at least one type of organizational change at baseline, being employed in private sector, working in professions requiring $<12$ years and between 13-15 years of formal education and high job demands. See table 2 for details.

\section{Variables}

Exposure measures. Exposure to organizational change was measured with six items with a dichotomous response ("yes"/"no"). Items pertained to different distinct types of organization-wide changes, inquiring whether the organization in which the employee worked had, within the last 12 months, carried out "reorganization", "downsizing", "lay-offs", partial company closure, "partial company outsourcing" or "change of company ownership/acquisition". The terms "downsizing" and "layoffs" are partly overlapping in referring to letting employees go, but in the current study "downsizing" refers to a temporary termination of contract with the chance of rehiring, while "layoffs" refers to a permanent termination of the job contract.

The work-unit (level two) predictor was constructed as the proportion of employees within each work unit who reported that change had taken place, ie, the proportion of employees within each for unit responding "yes" to the questions pertaining to the organizational changes. Outcome measure. Clinically relevant mental distress.

Table 2. Non-response analysis and attrition analysis. Non-response defined as not completing HSCL-10 at baseline. Attrition defined as completing HSCL-10 at baseline, but not at follow-up. [OR=odds ratio; $\mathrm{Cl}=$ confidence interval.]

\begin{tabular}{|c|c|c|c|c|}
\hline & \multicolumn{2}{|c|}{ Non-response } & \multicolumn{2}{|c|}{ Attrition } \\
\hline & OR & $95 \% \mathrm{Cl}$ & $\mathrm{OR}$ & $95 \% \mathrm{Cl}$ \\
\hline \multicolumn{5}{|l|}{ Sex } \\
\hline Female & 0.73 & $0.67-0.78$ & 0.94 & $0.85-1.04$ \\
\hline Male & 1 & 1 & 1 & 1 \\
\hline \multicolumn{5}{|l|}{ Age } \\
\hline $29-39$ & - & - & - & - \\
\hline$>39-49$ & 0.59 & $0.52-.68$ & 0.77 & $0.63-0.92$ \\
\hline$>49-59$ & 0.58 & $0.51-.66$ & 0.64 & $0.53-0.77$ \\
\hline$>59$ & 0.73 & $0.64-.83$ & 0.73 & $0.60-0.88$ \\
\hline \multicolumn{5}{|l|}{ Skill level (years) } \\
\hline$>15$ & 1 & 1 & 1 & 1 \\
\hline $13-15$ & 0.97 & $0.88-1.08$ & 1.45 & $1.25-1.67$ \\
\hline$>10-12$ & 1.20 & $1.09-1.32$ & 1.48 & $1.28-1.71$ \\
\hline \multicolumn{5}{|l|}{ Workplace } \\
\hline Public sector & 1 & 1 & 1 & 1 \\
\hline Private sector & 0.94 & $0.85-1.03$ & 1.19 & $1.05-1.35$ \\
\hline \multicolumn{5}{|l|}{ HSCL-10 } \\
\hline Above cut-off & & & 1 & 1 \\
\hline Below cut-off & & & 1.16 & $0.99-1.35$ \\
\hline \multicolumn{5}{|l|}{ Work Factors } \\
\hline Job Demands & & & 1.12 & $1.03-1.22$ \\
\hline Job Control & & & 0.89 & $0.82-0.96$ \\
\hline Social Support & & & 0.94 & $0.88-1.01$ \\
\hline \multicolumn{5}{|l|}{$\begin{array}{l}\text { Organization-wide } \\
\text { changes }\end{array}$} \\
\hline No change at baseline & & & 1 & 1 \\
\hline$\geq 1$ change at baseline & & & 1.12 & $1.00-1.25$ \\
\hline
\end{tabular}


Mental distress was measured with the ten-item Hopkins Symptom Checklist (HSCL-10) (37), a self-report instrument for assessing symptoms of mental distress (37-39). For each item presented, subjects were to rate their own experiences the last seven days on a four-point Likert-scale, ranging from " $1=$ not at all" to " $4=$ very much". Cronbach's $\alpha$ at baseline and follow-up were 0.86 and 0.87 . A cut-off point at a mean score of $\geq 1.85$ was set to identify subjects suffering from clinically relevant mental distress (39-41). By applying this cut-off, clinical depression has been detected with a specificity of $74 \%$ as defined by Composite International Diagnostic Interview (CIDI) (42) and the instrument has been utilized in prior population studies (43). The reliability and validity of HSCL-10 has been demonstrated in previous population studies $(37,39)$.

\section{Potential confounders}

Age, sex, and skill level were included in all analyses as potential confounders. Skill level was categorized using the International Standard Classification of Occupations (ISCO-88) (44). We utilized the following three categories: (i) $\leq 12$, (ii) $13-15$ and (iii) $>15$ years of formal education. Age was divided into four categories, (i) 29-39, (ii) $>39-49$, (iii) $>49-59$ and (iv) $>59$ years. Place of employment, ie, whether respondents were employed in private or public sector was also included as a potential confounder in all analyses.

In addition, the psychosocial work factors (i) job demands, (ii) job control and (iii) social support were included to determine the extent to which the effect of organizational change exerted a direct effect, irrespective of these factors. These factors were included as possible confounders or mediators in order to observe whether prospective associations between organizational change and mental distress attenuated upon their inclusion. The work factors were assessed by QPS Nordic (45). Responses on all items were given on a five-point Likert scale, ranging from " $1=$ very seldom or never" to " $5=$ very often or always". A mean score was calculated for all work factors separately. Cronbach's $\alpha$ at T1 was 0.83 for job control, 0.76 for job demands and 0.85 for social support.

\section{Statistical analyses}

Statistical analyses were run using IBM SPSS Statistics, version 24.0 (IBM Corp, Armonk, NY, USA) and R, version 3.4.4 (R Foundation for Statistical Computing, Vienna, Austria). The level of statistical significance was set to $\mathrm{P}<0.05$.

The multilevel analyses were conducted in three steps. In the first step (model 1), analyses were adjusted for age, sex, skill level, year of baseline measurement, number of employees in the work unit and place of employment (private or public sector). The second step (model 2) adjusted for mental distress/HSCL-10 at baseline in addition to the aforementioned, whereas the third step (model 3) also adjusted for the work factors job demands, job control and social support.

As employee responses were nested within work units, we conducted multilevel logistic regressions, or generalized logistic mixed effects regression (GLMER, estimated by the lme4 package in R) to assess prospective associations between exposure and outcome at both the individual- and work-unit level. Multilevel modelling takes into account possible clustering effects in the data, ie, bias due to non-independence of measurements within clusters. Not taking this into account may deflate standard error estimates and increase the risk of Type I error, especially if the intra-class correlation (ie, the correlation of responses within units) is high $(46,47)$. Intra class-correlations (ICC) reflect the within-group correlation of measurements and the degree to which variance can be explained by between-group differences (48). In the current study, the participating companies were diverse, varying considerably in size, from small, one-unit companies to large companies with many different units across several locations. Therefore, the work unit was used as the cluster variable as employees within work units should have more in common than employees within companies. This notion was supported by the ICC of the organizational change items being higher for work units than for companies (ranging $0.40-0.70$ for work units and $0.25-0.52$ for organizations).

The individual level predictor was group-mean centered $(49,50)$, ie, each employees' respective work-unit mean was subtracted from each individual score. Utilizing group-mean centering for the individual-level scores disentangles the effect of the predictor at the different levels by allowing for the predictor at the individual level (level one) and work-unit level (level two) to be uncorrelated. When the predictors at the different levels are uncorrelated, ie, the predictor at the individual level does not vary with the aggregated work-unit level predictor, the effect of the predictor on each level can be considered separately (50). Furthermore, since predictors are uncorrelated, including a group-mean centered individual level predictor in a multilevel analysis does not partial out the effect of the individual level predictor from the effect of the group-level predictor.

As we were interested in estimating the effect of the predictor at both the individual and work-unit level on employee mental distress, following recommendations by Enders \& Tofighi (50), group-mean centering was chosen over grand-mean centering.

To model variability, multilevel models utilize random effects, ie, random intercepts and random slopes. In multilevel modelling, a variance parameter can be specified 
for the intercept and the regression slope. In (i) a random intercept and random slope model, both the intercept and slope can vary between work-units. In (ii) a random intercept only model, the intercept varies between work-units, while the regression slope is fixed for all level two units, ie, the regression coefficient is the same for all workunits. Both random intercept only models and random intercept and random slope models were tested, and a likelihood ratio test was used to determine whether adding a random slope improved model fit, or whether the more parsimonious random intercept only model was sufficient.

\section{Results}

\section{Separate organizational changes}

According to the likelihood ratio tests, adding a random slope resulted in a statistically significant improvement only for the model with downsizing as predictor (Chi square $=4.606$, Chi Df $=1, \mathrm{P}<0.05$ ). Thus, all other models were run with a random intercept only.

In model 1 , at the individual level, all separate, organizational changes were statistically significantly associated with clinically relevant mental distress at follow-up: "reorganization" [odds ratio (OR) 1.50, 95\% confidence interval (CI) 1.22-1.83], "downsizing" (OR 1.70, 95\% CI 1.32-2.20), "lay-offs" (OR 1.49, 95\% CI 1.10-2.01) "partial closure" (OR 1.31, 95\% CI 1.00-1.70), "partial outsourcing" (OR 1.52, 1.12-2.06), and "merger/acquisition" (OR 1.50, 95\% CI 1.00-2.23). At the work-unit level, the associations were statistically significant for "reorganization" (OR 1.70, 95\% CI 1.26-2.30) and "partial outsourcing" (OR 1.90, 95\% CI 1.04-3.44). In model 2 , adding adjustment for mental distress at baseline, at the individual level, company "reorganization" (OR 1.33, 95\% CI 1.06-1.67) and "downsizing" (OR 1.47, 95\% CI
1.10-1.97) remained statistically significant, and - for the work-unit level - "reorganization" (OR 1.46, 95\% CI 1.04-2.04) was a statistically significant predictor. In model 3, adding psychosocial work factors as predictors, at the individual level company "reorganization" (OR 1.29, 95\% CI 1.01-1.65), "downsizing” (OR 1.51, 95\% CI 1.12-2.03) and "lay-offs" (OR1.46, 95\% CI 1.01-2.12) were statistically significant, whereas at work-unit level no associations remained statistically significant when adjusting for work factors. See table 3 for details.

\section{Multiple organizational changes}

In model 1, exposure to "one type of organizational change at T1" as opposed to none was statistically significantly associated with clinically relevant mental distress at follow-up for both the individual (OR 1.36, 95\% CI 1.07-1.72) and work-unit level (OR 1.98, 1.28-3.06). Exposure to "two or more changes at T1" were statistically significantly associated with clinically relevant mental distress at follow-up only at the individual level (OR 2.12, 95\% CI 1.64-2.73). In model 2, associations between exposure to "one type of change at $\mathrm{T} 1$ " remained statistically significant at both individual level (OR 1.43, 95\% CI 1.10-1.85) and work-unit level (OR 1.73, 95\% CI 1.06-2.83). Associations also remained significant for exposure to "two or more changes at T1" at the individual level (OR 1.86, 95\% CI 1.39-2.49). In model 3, associations remained statistically significant at the individual level for exposure to "one type of change at T1" (OR $1.41,95 \%$ CI 1.07-1.87) and "two or more of changes at T1" (OR 1.75, 95\% CI 1.28-2.38). See table 4 for details.

\section{Repeated organizational change}

In model 1, exposure to organizational change "both at T1 and T2" were statistically significantly associated with clinically relevant mental distress at follow-up

Table 3. Separate organizational changes. Multilevel logistic regressions with clinically relevant mental distress (HSCL-10) at follow-up as outcome. Predictors at the individual level were the reported changes at baseline and predictors at the work-unit level were the proportion of employees in each work unit reporting the respective changes.[OR=odds ratio; $\mathrm{Cl}=$ confidence interval.] Bold indicates statistically significant.

\begin{tabular}{|c|c|c|c|c|c|c|c|c|c|c|c|c|}
\hline \multirow{3}{*}{$\begin{array}{l}\text { Organizational } \\
\text { change }\end{array}$} & \multicolumn{4}{|c|}{ Model $1^{\text {a }}$} & \multicolumn{4}{|c|}{ Model $2^{\mathrm{b}}$} & \multicolumn{4}{|c|}{ Model $3^{c}$} \\
\hline & \multicolumn{2}{|c|}{ Individual-level } & \multicolumn{2}{|c|}{ Work-unit level } & \multicolumn{2}{|c|}{ Individual level } & \multicolumn{2}{|c|}{ Work-unit level } & \multicolumn{2}{|c|}{ Individual level } & \multicolumn{2}{|c|}{ Work-unit level } \\
\hline & OR & $95 \% \mathrm{Cl}$ & OR & $95 \% \mathrm{Cl}$ & OR & $95 \% \mathrm{Cl}$ & OR & $95 \% \mathrm{Cl}$ & $\mathrm{OR}$ & $95 \% \mathrm{Cl}$ & OR & $95 \% \mathrm{Cl}$ \\
\hline Reorganization & 1.50 & $1.22-1.83$ & 1.70 & $1.26-2.30$ & 1.33 & $1.06-1.67$ & 1.46 & $1.04-2.04$ & 1.29 & $1.01-1.65$ & 1.41 & $0.97-2.04$ \\
\hline Downsizing ${ }^{d}$ & 1.70 & $1.32-2.20$ & 0.81 & $0.56-1.18$ & 1.47 & $1.10-1.97$ & 0.75 & $0.50-1.14$ & 1.51 & $1.12-2.03$ & 0.66 & $0.42-1.05$ \\
\hline Layoffs $^{d}$ & 1.49 & $1.10-2.01$ & 1.00 & $0.52-1.91$ & 1.35 & $0.96-1.92$ & 0.81 & $0.39-1.70$ & 1.46 & $1.01-2.12$ & 0.52 & $0.23-1.21$ \\
\hline Partial closure & 1.31 & $1.00-1.70$ & 1.55 & $0.97-2.47$ & 1.16 & $0.86-1.57$ & 1.44 & $0.84-2.47$ & 0.98 & $0.71-1.36$ & 1.42 & $0.79-2.54$ \\
\hline Partial outsourcing & 1.52 & $1.12-2.06$ & 1.90 & $1.04-3.44$ & 1.34 & $0.94-1.91$ & 1.44 & $0.74-2.83$ & 1.24 & $0.84-1.82$ & 1.45 & $0.69-3.05$ \\
\hline $\begin{array}{l}\text { Change of ownership/ } \\
\text { acquisition }\end{array}$ & 1.50 & $1.00-2.23$ & 0.84 & $0.40-1.77$ & 1.32 & $0.84-2.08$ & 0.73 & $0.31-1.68$ & 1.20 & $0.75-1.93$ & 0.82 & $0.33-2.01$ \\
\hline
\end{tabular}

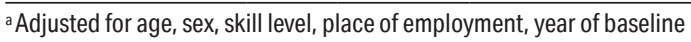

${ }^{\mathrm{b}}$ Model $1+$ mental distress (HSLC-10) at baseline

c Model 2+ and the work factors job demands, job control and social support.

${ }^{\mathrm{d}}$ Downsizing pertains to temporary termination of job contract, while layoffs pertains to permanent termination of job contract. 
Table 4. Multiple organizational change. Multilevel logistic regressions with clinically relevant mental distress (HSCL-10) at follow-up as outcome. Predictors at the individual level were the reported changes at baseline and predictors at the work-unit level were the proportion of employees in each work unit reporting the respective changes. [OR=odds ratio; $\mathrm{Cl}=$ confidence interval.] Bold indicates statistically significant.

\begin{tabular}{|c|c|c|c|c|c|c|c|c|c|c|c|c|}
\hline \multirow{3}{*}{$\begin{array}{l}\text { Organizational } \\
\text { change }\end{array}$} & \multicolumn{4}{|c|}{ Model $1^{\text {a }}$} & \multicolumn{4}{|c|}{ Model $2^{b}$} & \multicolumn{4}{|c|}{ Model $3^{c}$} \\
\hline & \multicolumn{2}{|c|}{ Individual-level } & \multicolumn{2}{|c|}{ Work-unit level } & \multicolumn{2}{|c|}{ Individual level } & \multicolumn{2}{|c|}{ Work-unit level } & \multicolumn{2}{|c|}{ Individual level } & \multicolumn{2}{|c|}{ Work-unit level } \\
\hline & OR & $95 \% \mathrm{Cl}$ & OR & $95 \% \mathrm{Cl}$ & OR & $95 \% \mathrm{Cl}$ & OR & $95 \% \mathrm{Cl}$ & OR & $95 \% \mathrm{Cl}$ & OR & $95 \% \mathrm{Cl}$ \\
\hline 0 change at T1 & 1 & & 1 & & 1 & & 1 & & 1 & & 1 & \\
\hline 1 change at $\mathrm{T} 1$ & 1.36 & $1.07-1.72$ & 1.98 & $1.28-3.06$ & 1.43 & $1.10-1.85$ & 1.73 & $1.06-2.83$ & 1.41 & $1.07-1.87$ & 1.63 & $0.95-2.79$ \\
\hline$\geq 2$ changes at $T 1$ & 2.12 & $1.64-2.73$ & 1.44 & $0.98-2.12$ & 1.86 & $1.39-2.49$ & 1.12 & $0.73-1.73$ & 1.75 & $1.28-2.38$ & 1.00 & $0.62-1.61$ \\
\hline
\end{tabular}

adjusted for age, sex, skill level, place of employment, year of baseline

${ }^{b}$ Model 1+ mental distress (HSLC-10) at baseline

${ }^{c}$ Model 2+ and the work factors job demands, job control and social support.

Table 5. Repeated organizational change. Multilevel logistic regressions with clinically relevant mental distress (HSCL-10) at follow-up as outcome. Predictors at the individual level were the reported changes at baseline and predictors at the work-unit level were the proportion of employees in each work unit reporting the respective changes at baseline.[OR=odds ratio; $\mathrm{Cl}=$ confidence interval.] Bold indicates statistically significant.

\begin{tabular}{|c|c|c|c|c|c|c|c|c|c|c|c|c|}
\hline \multirow{3}{*}{$\begin{array}{l}\text { Organizational } \\
\text { change }\end{array}$} & \multicolumn{4}{|c|}{ Model $1^{\text {a }}$} & \multicolumn{4}{|c|}{ Model $2^{b}$} & \multicolumn{4}{|c|}{ Model 3c } \\
\hline & \multicolumn{2}{|c|}{ Individual-level } & \multicolumn{2}{|c|}{ Work-unit level } & \multicolumn{2}{|c|}{ Individual level } & \multicolumn{2}{|c|}{ Work-unit level } & \multicolumn{2}{|c|}{ Individual level } & \multicolumn{2}{|c|}{ Work-unit level } \\
\hline & $\mathrm{OR}$ & $95 \% \mathrm{Cl}$ & $\mathrm{OR}$ & $95 \% \mathrm{Cl}$ & $\mathrm{OR}$ & $95 \% \mathrm{Cl}$ & OR & $95 \% \mathrm{Cl}$ & OR & $95 \% \mathrm{Cl}$ & $\mathrm{OR}$ & $95 \% \mathrm{Cl}$ \\
\hline 0 change at T1 & 1 & & 1 & & 1 & & 1 & & 1 & & 1 & \\
\hline Change only at T1 & 1.03 & $0.76-1.41$ & 2.13 & $1.29-3.52$ & 0.93 & $0.66-1.31$ & 2.02 & $1.15-3.56$ & 0.91 & $0.63-1.32$ & 1.79 & $0.97-3.32$ \\
\hline Change only at T2 & 1.03 & $0.72-1.49$ & 1.56 & $0.82-2.99$ & 0.94 & $0.62-1.41$ & 1.47 & $0.71-3.03$ & 0.93 & $0.60-1.44$ & 1.29 & $0.59-2.82$ \\
\hline Changes at $\mathrm{T} 1$ and $\mathrm{T} 2$ & 2.04 & $1.52-2.74$ & 1.91 & $1.26-2.89$ & 1.93 & $1.39-2.70$ & 1.59 & $0.99-2.49$ & 1.84 & $1.29-2.63$ & 1.37 & $0.83-2.27$ \\
\hline
\end{tabular}

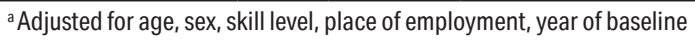

${ }^{\mathrm{b}}$ Model $1+$ mental distress (HSLC-10) at baseline

${ }^{c}$ Model 2+ and the work factors job demands, job control and social support.

for both individual level exposure (OR 2.04, 95\% CI 1.52-2.74) and work-unit level exposure (OR 1.92, 95\% CI 1.26-2.89). In model 2, the association between exposure to change at "both T1 and T2" remained significant only for the individual level (OR 1.93, 95\% CI $1.39-2.70)$, whereas exposure to "one type of change at T1" was statistically significant for work-unit level (OR 2.02, 95\% CI 1.15-3.56). In model 3, the associations between exposure to change at "both T1 and T2" remained statistically significant for the individual level (OR 1.84, 95\% CI 1.29-2.63). See table 5 for details.

\section{Discussion}

\section{Separate organizational change}

Organizational change may affect the organization as a whole, departments, work units and individual employees. Applying multilevel analyses, the current study aimed to elucidate the effects of exposure to various distinct types and patterns of organizational change at both individual- and work-unit level on employee subsequent clinically relevant mental distress. The present results indicate a long-term detrimental effect on employee mental health following exposure to separate, co-occuring or repeated organizational change at either level.

The study demonstrated prospective associations between individual- and work-unit level exposure to certain types of separate organizational changes, eg, company reorganization, and clinically relevant mental distress two years after change had taken place. However, following exposure at the individual level, some statistically significant associations diminished when adjusting for psychosocial work factors, whereas all statistically significant associations diminished at workunit level when adjusting for these factors. This suggests that the relationship between exposure to organizational change at work-unit level and employee mental distress could be mediated by repercussions in the work environment. However, following exposure on the individual level, associations remained statistically significant for reorganization, downsizing, and layoffs, suggesting health effects that are not derived from changes in demands, control, or support at the individual level. Although much attention has been given to the relationship between organizational change and employee mental health, the mechanisms explaining how and why different types of organizational changes affect employee health are yet largely unknown (12). One potential mechanism could involve how organizational change influences factors in the work environment, and by that employee health. Different types of organizational changes may be associated with distinct changes in the work environment affecting employee health differently. Empirically supported theoretical frameworks such as the demand-control-support model (34), and the 
effort-reward model (51) posit how work factors such as job control, job demands, and job security can influence employee health and well-being $(52,53)$, and prior studies have reported increased job demands, reduced job control (20) and social support (54) following extensive organizational changes, such as company downsizing. If certain types of organizational change is associated with specific changes in the work environment known to affect mental health negatively, this could help explain the different associations between the various types of organizational change and subsequent mental distress, as is indicated in the present results.

Differences in change content could also help explain why only certain types of organizational change is associated with long-term mental distress. For instance, differences in content may influence how the change is perceived and thus responded to. If the content of an organizational change is perceived as posing a threat to job security (55-57), which may be the case in a downsizing or layoff process where ones job contract may be temporarily or permanently terminated, experiencing such change may be associated with elevated levels of distress. While on the other hand, exposure to organizational changes that consists of elements perceived as opportunities for positive development and growth, eg, a company merger, may not be associated with mental distress. In other words, differences in change content may be associated with differences in change appraisal, which may influence whether change is experienced as straining or not, possibly explaining why some organizational changes are associated with mental distress, while others are not, as was the case in the present study.

In addition, change implementation and process may also influence how organizational change is related to long-term mental distress. It seems reasonable to expect that the manner in which change is undertaken may differ greatly between specific change processes of similar content. Two downsizing processes, for instance, may affect employee health differently as a function of the way and context in which they were implemented. Differences in various aspects in the change process such as the degree to which employees are included in the process, sense of procedural justice, leadership style and information flow could all reflect differences in change implementation, which may affect employee health differently (58-60). Such variations in aspects pertaining to change process may help explain the inconsistent findings related to health effects following organizational changes of similar content (12) and may also help explain why previously reported associations between organizational changes such as company closure and outsourcing and mental distress was not replicated in the current study $(12,61)$.

\section{Multiple and repeated organizational change}

Although recurrent change is a central characteristic of contemporary work life (1) few studies have examined the effects following multiple or repeated organizational changes on employee mental health $(12,13)$. In the present study, results pertaining to the effects following exposure to multiple organizational changes at the individual level indicated a long-term association with clinically relevant mental distress. A statistically significant association was not present following exposure at work-unit level. In line with prior studies, effects following multiple changes were stronger than for a one-time only exposure to organizational change at baseline (62-65). For exposure to repeated organizational changes, both individual level and work-unit level exposure were statistically significantly associated with clinically relevant distress at follow-up, but associations at work-unit level diminished when adjusting for mental distress at baseline and the psychosocial work factors.

The psychological load of organizational change may be derived not only from exposure to the specific types of change and the accompanying process, but also from the number of different changes, how often they occur, and how long they last. To help explain the stronger effects on health following multiple and repeated changes as opposed to separate changes, one may speculate as to whether the work environment in organizations undergoing multiple or repeated organizational changes could be more strongly affected than in companies undergoing a one-time only, separate change. For instance, there may be an elevated level of uncertainty, increases in workload or decrease in social support in organizations undergoing repeated, extensive changes compared to organizations undergoing a single, distinct change. In addition to affecting the work environment, and by that employee health, multiple or repeated organizational changes could also in itself possess a greater threat to perceived stability and sense of predictability in both the individual employee and the organization than a separate, discrete change. To help explain the stronger effect associated with multiple and repeated changes compared to separate changes in the present study, one could draw upon vulnerability models (63). Vulnerability models posit that the individual can become more vulnerable following repeated exposure to a stressor, as it drains the individual's coping resources and over time could make the individual less capable of coping $(66,67)$. If exposure to organizational change is perceived as straining, repeated exposures to such changes could have a more adverse impact on health than a one-time exposure as the employee repeatedly has to mobilize effort to cope, which eventually may lead to fatigue and emotional exhaustion. 
Previous studies examining the health effects of both separate and repeated organizational changes such as reorganizations, downsizing and layoffs have reported associations with mental distress (68), depressive symptoms $(6,62,69-72)$ and symptoms of anxiety (73), as in the present study. In addition, other health-related outcomes such as disability pension (10), increases in sick leave $(3,4)$ and psychotropic drug use (2) have all been associated with separate organizational changes, such as the aforementioned. However, not all studies reports these negative health effects following change (12). Current results did not identify statistically significantly prospective associations between clinically relevant distress and organizational changes such as partial closure and outsourcing, underlining that organizational change of different scopes may have different effects on employee health based on the various potential mechanisms as mentioned above. Regarding exposure to repeated change, in addition to health effects like heightened levels of mental distress $(63,64,68)$ and anxiety (73), effects such as increased job insecurity, role ambiguity and intention to quit (62), higher selfrated workload, lowered job satisfaction (64), reduced trust and turnover intention (74) have been reported. As in the present study, multiple changes have also been associated with stronger effects on employee health than single change (62-64). However, there have also been reports on positive effects of repeated organizational change such as increased resilience and autonomy (74). Thus, the relationship between organizational change and employee health hence is still pending and the various pathways between different types and patterns of change and employee mental distress needs to be examined more in detail.

\section{Methodological considerations}

The present study utilized a prospective design with two-year intervals between measurements, which may have influenced results. The lack of associations between certain types of organizational change and mental distress could be due to the long time-span between measurements not being optimal. Effects may have been present but diminished within the time span between baseline and follow-up. Thus, even though results did not indicate a statistically significant detrimental health effect following certain types organizational changes two years after exposure, a short-term effect could still be present (12).

In addition, the current study used a clinical cut-off as outcome measure. This is a strict criterion, hence, although the aim of the current study pertained to clinical levels of distress, there may be undetected associations of change with sub-clinical levels of distress. To our knowledge, few other comparable studies have applied a clinical cut-off. Furthermore, with depression being one of the leading causes of sick leave and work disability $(1,27)$ the notion that organizational change efforts may cause mental distress of an intensity that may necessitate medical intervention is of importance. The relationships demonstrated herein highlight the need to take employee mental health into account when initiating and implementing organizational change, especially when multiple, repeated changes are taking place.

Attrition may also affect the results. The attrition analysis indicated that experiencing at least one type of organizational change was associated with drop-out. If subjects dropped out due to the impact of organizational change on mental health, this could affect the internal validity of the study, suggesting an underestimation of effects. In addition, although scoring above HSCL10 cut-off at baseline was not significantly associated with drop-out at follow-up, it cannot be ruled out that employees already experiencing clinically relevant mental distress, possibly due to organizational change at baseline, were less likely to participate initially, implying a healthy worker effect (75).

Furthermore, a larger part of the sample was employed in public sector and had permanent positions than the general working population of Norway (76). Previous studies have indicated that temporary employment is linked to higher psychological morbidity (77-79), and one may surmise that temporary employees may experience certain types of change as more threatening than permanent employees. Furthermore, employees working in temporary positions in private companies have been reported to experience a higher physical workload than their publicly employed counterparts (80). Hence, effects in the current study could be underestimated due to the large proportion of respondents with a presumably relatively secure work situation.

The analyses of repeated organizational change included measurements of both predictor and outcome at follow-up, hence the temporal separation of predictor and outcome was only partial, meaning the design is only partly longitudinal. However, effects were stronger for experiencing change at both $\mathrm{T} 1$ and $\mathrm{T} 2$ than for experiencing it only at $\mathrm{T} 1$ or only at $\mathrm{T} 2$, suggesting these analyses picked up something more than the cross-sectional association of T2 change with T2 mental distress.

All data were collected using questionnaires, hence results could be influenced by self-report bias and common-method variance (CMV) $(81,82)$. However, a multilevel design should attenuate such bias. Demonstrating an effect at the aggregated work unit level should minimize reporting bias that may occur at the individual level. However, it should be kept in mind that not detecting associations at work-unit level (level two) does not constitute evidence of such reporting bias 
at the individual level (level one), since the association between organizational change and employee mental health could be largely an individual level phenomenon, and statistical power at the work-unit level is lower due to fewer observations.

\section{Future perspectives}

The prospective associations between certain types and patterns of organizational change and clinically relevant mental distress in the present study underline the need to take into account employee health when planning and implementing extensive, organization-wide changes as this may have long-term adverse consequences for both employees and the organization. In line with prior studies, the present results demonstrate that organizational change is a heterogeneous phenomenon with certain types of changes being more consistently associated with detrimental health effects than other types of change (12) and a more in-depth understanding of the underlying mechanisms as to how exposure to various types of organizational change affects employee health differently is needed. Future research should consider possible mediating or moderating variables in the relationship between exposure to organizational changes and employee health. For instance, organizational change may influence the work environment in ways that may influence employee health, hence mediate the relationship between change and employee health. Prior studies have suggested that psychological and social work factors such as job demands and control $(53,83)$, job insecurity (57), role conflict and ambiguity $(84,85)$, leadership $(86,87)$, and supervisor- and social support $(53,85)$ may influence employee health and these factors may be affected by change taking place within the organization. Furthermore, organizational and employee characteristics might moderate the relationship between organizational changes and mental health outcomes. Further knowledge of the potential moderating effects of eg, leadership style, employee age, occupation or work organization could give rise to targeted interventions in order to reduce and prevent adverse health effects associated with adverse and costly health outcomes. It remains an important task of future research to further examine under what specific conditions a negative or positive effect occurs.

\section{Acknowledgements}

The authors would like to thank Elisabeth Petersen, Shahrooz Elka, Jan S. Emberland, Bjørn Lau, Anne Lene Andersen and Margrethe Schøning for their help in the survey administration. We also thank all companies participating in the study.

\section{Funding}

The Research Council of Norway (grant number 185209 and 158284), the Norwegian Ministry of Labour and Social Affairs and the Norwegian Labour Inspection Authority funded the current study. The funders had no involvement in study design, data collection, analyses, interpretation of the data or writing the manuscript.

\section{References}

1. EUROFOUND. First Findings: Sixth European Working Conditions Survey: Résumé. Luxembourg: Office for Official Publications of the European Communities: European Foundation for the Improvement of Living and Working Conditions, European Union, 20169289714298.

2. Kivimäki M, Honkonen T, Wahlbeck K, Elovainio M, Pentti J, Klaukka T, et al. Organisational downsizing and increased use of psychotropic drugs among employees who remain in employment. J of Epi Com Health. 2007;61(2):154-8. https:// doi.org/10.1136/jech.2006.050955

3. Vahtera J, Kivimaki M, Pentti J. Effect of organisational downsizing on health of employees. The Lancet. 1997;350(9085):1124-8. https://doi.org/10.1016/S01406736(97)03216-9

4. Vahtera J, Kivimäki M, Pentti J, Linna A, Virtanen M, Virtanen P, et al. Organisational downsizing, sickness absence, and mortality: 10-town prospective cohort study. Bmj. 2004;328(7439):555. https://doi.org/10.1136/ bmj.37972.496262.0D

5. Greubel J, Kecklund G. The impact of organizational changes on work stress, sleep, recovery and health. Ind Health. 2011;49(3):353-64. https://doi.org/10.2486/indhealth.MS1211

6. Netterstrøm B, Blønd M, Nielsen M, Rugulies R, Eskelinen L. Development of depressive symptoms and depression during organizational change-a two-year follow-up study of civil servants. Scand J Work Environ Health. 2010:445-8. https:// doi.org/10.5271/sjweh.3075

7. Ahola K, Kivimäki M, Honkonen T, Virtanen M, Koskinen $\mathrm{S}$, Vahtera J, et al. Occupational burnout and medically certified sickness absence: a population-based study of Finnish employees. J of Psych Res. 2008;64(2):185-93. https://doi. org/10.1016/j.jpsychores.2007.06.022

8. Ferrie JE, Shipley MJ, Marmot MG, Stansfeld S, Smith GD. Health effects of anticipation of job change and nonemployment: longitudinal data from the Whitehall II study. Bmj. 1995;311(7015):1264-9. https://doi.org/10.1136/ bmj.311.7015.1264

9. Hansson A-S, Vingård E, Arnetz BB, Anderzén I. Organizational change, health, and sick leave among health care employees: 
A longitudinal study measuring stress markers, individual, and work site factors. Work \& Stress. 2008;22(1):69-80. https:// doi.org/10.1080/02678370801996236

10. Vahtera J, Kivimäki M, Forma P, Wikström J, Halmeenmäki $\mathrm{T}$, Linna A, et al. Organisational downsizing as a predictor of disability pension: the 10-town prospective cohort study. J Epi Comm Health. 2005;59(3):238-42. https://doi.org/10.1136/ jech.2004.021824

11. Breinegaard N, Jensen JH, Bonde JP. Organizational change, psychosocial work environment, and non-disability early retirement: a prospective study among senior public employees. Scand J Work Environ Health. 2017;43(3):234-40. https://doi.org/10.5271/sjweh.3624

12. Oreg S, Vakola M, Armenakis A. Change recipients' reactions to organizational change A 60 -year review of quantitative studies. J Appl Behav Sci. 2011;47(4):461-524. https://doi. org/10.1177/0021886310396550

13. Klarner P, By RT, Diefenbach T. Employee emotions during organizational change-Towards a new research agenda. Scand J Managem. 2011;27(3):332-40. https://doi. org/10.1016/j.scaman.2011.06.002

14. Bliese PD, Edwards JR, Sonnentag S. Stress and well-being at work: A century of empirical trends reflecting theoretical and societal influences. J App Psych. 2017;102(3):389. https://doi. org/10.1037/ap10000109

15. Meurs JA, Perrewé PL. Cognitive activation theory of stress: An integrative theoretical approach to work stress. J Managem. 2011;37(4):1043-68. https://doi. org/10.1177/0149206310387303

16. Bamberger SG, Vinding AL, Larsen A, Nielsen $\mathrm{P}$, Fonager $\mathrm{K}$, Nielsen $\mathrm{RN}$, et al. Impact of organisational change on mental health: a systematic review. Occup Environ Med. 2012;69(8):592-8. https://doi.org/10.1136/ oemed-2011-100381

17. Moore S, Grunberg L, Greenberg E. Repeated downsizing contact: the effects of similar and dissimilar layoff experiences on work and well-being outcomes. J Occ Health Psych. 2004;9(3):247. https://doi.org/10.1037/1076-8998.9.3.247

18. Kivimäki M, Vahtera J, Pentti J, Thomson L, Griffiths A, Cox T. Downsizing, changes in work, and self-rated health of employees: A 7-year 3-wave panel study. Anx, Stress and Cop . 2001;14(1):59-73. https://doi. org/10.1080/10615800108248348

19. Breinegaard N, Jensen JH, Bonde JP. Organizational change, psychosocial work environment, and non-disability early retirement: a prospective study among senior public employees. Scand J Work Environ Health . 2017;43(3):234-40. https://doi.org/10.5271/sjweh.3624

20. Kivimäki M, Vahtera J, Pentti J, Ferrie JE. Factors underlying the effect of organisational downsizing on health of employees: longitudinal cohort study. Bmj. 2000;320(7240):971-5. https:// doi.org/10.1136/bmj.320.7240.971

21. Geuskens GA, Koppes LL, van den Bossche SN, Joling CI. Enterprise restructuring and the health of employees: a cohort study. J Occup Environ Med. 2012;54(1):4-9. https://doi. org/10.1097/JOM.0b013e31823c766e
22. Lopez AD, Murray CC. The global burden of disease, 1990-2020. Nature Med 1998;4(11):1241. https://doi. org/10.1038/3218

23. Kinge JM, Sælensminde K, Dieleman J, Vollset SE, Norheim OF. Economic losses and burden of disease by medical conditions in Norway. Health Policy. 2017;121(6):691-8. https://doi.org/10.1016/j.healthpol.2017.03.020

24. OECD. Fit Mind, Fit Job2015; Paris: OECD 2015.

25. Whooley MA, Kiefe CI, Chesney MA, Markovitz JH, Matthews K, Hulley SB. Depressive symptoms, unemployment, and loss of income: The CARDIA Study. Archiv of Intern Med. 2002;162(22):2614-20. https://doi. org/10.1001/archinte.162.22.2614

26. Luppa M, Heinrich S, Angermeyer MC, König H-H, RiedelHeller SG. Cost-of-illness studies of depression: a systematic review. J Affect Disord. 2007;98(1):29-43. https://doi. org/10.1016/j.jad.2006.07.017

27. Sobocki P, Jönsson B, Angst J, Rehnberg C. Cost of depression in Europe. J Ment Health Pol Econ. 2006;9(2):87-98.

28. Olesen J, Gustavsson A, Svensson M, Wittchen HU, Jönsson B. The economic cost of brain disorders in Europe. Eur $\mathrm{J}$ Neuro. 2012;19(1):155-62. https://doi.org/10.1111/j.14681331.2011.03590.x

29. Stewart WF, Ricci JA, Chee E, Hahn SR, Morganstein D. Cost of lost productive work time among US workers with depression. Jama. 2003;289(23):3135-44. https://doi. org/10.1001/jama.289.23.3135

30. Adler DA, McLaughlin TJ, Rogers WH, Chang H, Lapitsky L, Lerner D. Job performance deficits due to depression. Am J Psych. 2006;163(9):1569-76. https://doi.org/10.

31. Lerner D, Henke RM. What does research tell us about depression, job performance, and work productivity? J Occup Environ Med. 2008;50(4):401-10. https://doi.org/10.1097/ JOM.0b013e31816bae50

32. Broadhead WE, Blazer DG, George LK, Tse CK. Depression, disability days, and days lost from work in a prospective epidemiologic survey. Jama. 1990;264(19):2524-8. https://doi. org/10.1001/jama.1990.03450190056028

33. Van der Doef M, Maes S. The job demand-control (-support) model and psychological well-being: a review of 20 years of empirical research. Work \& stress. 1999;13(2):87-114. https:// doi.org/10.1080/026783799296084

34. Karasek R. Demand/Control model: A social-emotional, and psychological approach to stress risk and active behavior development. ILO encyclopedia of occupational health and safety: ILO; 1998.

35. Väänänen A, Koskinen A, Joensuu M, Kivimäki M, Vahtera J, Kouvonen A, et al. Lack of predictability at work and risk of acute myocardial infarction: An 18-year prospective study of industrial employees. Am J Pub Health. 2008;98(12):2264-71. https://doi.org/10.2105/AJPH.2007.122382

36. Paulsen N, Callan VJ, Grice TA, Rooney D, Gallois $\mathrm{C}$, Jones E, et al. Job uncertainty and personal control during downsizing: A comparison of survivors and victims. Hum Relat. 2005;58(4):463-96. https://doi. org/10.1177/0018726705055033 
37. Haavet OR, Sirpal MK, Haugen W, Christensen KS. Diagnosis of depressed young people in primary health care-a validation of HSCL-10. Fam Pract. 2010; 28(2): 233-37. https://doi.org/10.1093/fampra/cmq078

38. Sirpal MK, Haugen W, Sparle K, Haavet OR. Validation study of HSCL-10, HSCL-6, WHO-5 and 3-key questions in 14-16 year ethnic minority adolescents. Fam Pract. 2016;17(1):7. https://doi.org/10.1186/s12875-016-0405-3

39. Søgaard AJ, Bjelland I, Tell GS, Røysamb E. A comparison of the CONOR Mental Health Index to the HSCL-10 and HADS. Nor Epidem. 2003;13(2):279-84.

40. Lien L, Green K, Welander-Vatn A, Bjertness E. Mental and somatic health complaints associated with school bullying between 10 th and 12 th grade students; results from cross sectional studies in Oslo, Norway. Clin Epidem Ment Health. 2009;5(1):6. https://doi.org/10.1186/1745-0179-5-6

41. Thapa SB, Dalgard OS, Claussen B, Sandvik L, Hauff E. Psychological distress among immigrants from highand low-income countries: findings from the Oslo Health Study. Nor J Psych. 2007;61(6):459-65. https://doi. org/10.1080/08039480701773261

42. Sandanger I, Moum T, Ingebrigtsen G, Dalgard O, Sørensen T, Bruusgaard D. Concordance between symptom screening and diagnostic procedure: the Hopkins Symptom Checklist-25 and the Composite International Diagnostic Interview I. Soc Psych Epidem. 1998;33(7):345-54. https://doi.org/10.1007/ s001270050064

43. Strand BH, Dalgard OS, Tambs K, Rognerud M. Measuring the mental health status of the Norwegian population: a comparison of the instruments SCL-25, SCL-10, SCL-5 and MHI-5 (SF-36). Nor J Psych. 2003;57(2):113-8. https://doi. org/10.1080/08039480310000932

44. Elias P. Occupational Classification (ISCO-88). 1997.

45. Wännström I, Peterson U, Åsberg M, Nygren Å, Gustavsson JP. Psychometric properties of scales in the General Nordic Questionnaire for Psychological and Social Factors at Work (QPSNordic): Confirmatory factor analysis and prediction of certified long-term sickness absence. Scand J Psych. 2009;50(3):231-44. https://doi.org/10.1111/j.14679450.2008.00697.x

46. Julian MW. The consequences of ignoring multilevel data structures in nonhierarchical covariance modeling. Struct Equat Mod. 2001;8(3):325-52. https://doi.org/10.1207/ S15328007SEM0803_1

47. Bliese PD, Hanges PJ. Being both too liberal and too conservative: The perils of treating grouped data as though they were independent. Orga Res Methods. 2004;7(4):400-17. https://doi.org/10.1177/1094428104268542

48. Twisk JW. Applied multilevel analysis: a practical guide for medical researchers: Cambridge University Press; 2006. https://doi.org/10.1017/CBO9780511610806

49. Bell A, Jones K, Fairbrother M. Understanding and misunderstanding group mean centering: a commentary on Kelley et al.'s dangerous practice. Quality \& Quantity. 2018;52(5):2031-6. https://doi.org/10.1007/s11135-0170593-5
50. Enders CK, Tofighi D. Centering predictor variables in crosssectional multilevel models: a new look at an old issue. Psych Method. 2007;12(2):121. https://doi.org/10.1037/1082989X.12.2.121

51. Siegrist J, Starke D, Chandola T, Godin I, Marmot M, Niedhammer I, et al. The measurement of effort-reward imbalance at work: European comparisons. Soc Scien \& Med. 2004;58(8):1483-99. https://doi.org/10.1016/S02779536(03)00351-4

52. Stansfeld S, Candy B. Psychosocial work environment and mental health - a meta-analytic review. Scand J Work Environ Health. 2006:443-62. https://doi.org/10.5271/sjweh.1050

53. Nieuwenhuijsen K, Bruinvels D, Frings-Dresen M. Psychosocial work environment and stress-related disorders: A systematic review. Occ Med. 2010;60:277-86. https://doi. org/10.1093/occmed/kqq081

54. Head J, Kivimäki M, Martikainen P, Vahtera J, Ferrie JE, Marmot MG. Influence of change in psychosocial work characteristics on sickness absence: the Whitehall II study. J Epi Comm Health. 2006;60(1):55-61. https://doi.org/10.1136/ jech.2005.038752

55. Ferrie JE, Shipley MJ, Marmot MG, Stansfeld S, Smith GD. The health effects of major organisational change and job insecurity. Soc Sci Med. 1998;46(2):243-54. https://doi. org/10.1016/S0277-9536(97)00158-5

56. Ferrie JE, Shipley MJ, Stansfeld SA, Marmot MG. Effects of chronic job insecurity and change in job security on self reported health, minor psychiatric morbidity, physiological measures, and health related behaviours in British civil servants: the Whitehall II study. J Epi Com Health. 2002;56(6):450-4. https://doi.org/10.1136/jech.56.6.450

57. Sverke M, Hellgren J, Näswall K. No security: a meta-analysis and review of job insecurity and its consequences. J Occ Health Psych. 2002;7(3):242.https://doi.org/10.1037/10768998.7.3.242

58. Armenakis AA, Harris SG, Mossholder KW. Creating readiness for organizational change. Hum Relat. 1993;46(6):681-703. https://doi.org/10.1177/001872679304600601

59. Bordia P, Hobman E, Jones E, Gallois C, Callan VJ. Uncertainty during organizational change: Types, consequences, and management strategies. J Business Psych. 2004;18(4):507-32. https://doi.org/10.1023/B:JOBU.0000028449.99127.f7

60. Bommer WH, Rich GA, Rubin RS. Changing attitudes about change: Longitudinal effects of transformational leader behavior on employee cynicism about organizational change. J Org Behav. 2005;26(7):733-53. https://doi.org/10.1002/ job. 342

61. Belcourt M. Outsourcing - The benefits and the risks. Hum Res Man Rev. 2006;16(2):269-79. https://doi.org/10.1016/j. hrmr.2006.03.011

62. Moore S, Grunberg L, Greenberg E. Repeated downsizing contact: the effects of similar and dissimilar layoff experiences on work and well-being outcomes. J Occ Health Psych. 2004;9(3):247. https://doi.org/10.1037/1076-8998.9.3.247

63. Moore S, Grunberg L, Greenberg E. Surviving repeated waves 
of organizational downsizing: The recency, duration, and order effects associated with different forms of layoff contact. Anxiety, stress, and coping. 2006;19(3):309-29. https://doi. org/10.1080/10615800600901341

64. Isaksson K, Hellgren J, Pettersson P. Repeated downsizing: Attitudes and well-being for surviving personnel in a Swedish retail company. Health effects of the new labour market: Springer; 2002. p. 85-101.

65. Tsutsumi A, Nagami M, Morimoto K, Matoba T. Responsiveness of measures in the effort-reward imbalance questionnaire to organizational changes. J Psychosom Res. 2002;52(4):249-56. https://doi.org/10.1016/S00223999(02)00291-X

66. Zapf D, Dormann C, Frese M. Longitudinal studies in organizational stress research: a review of the literature with reference to methodological issues. J Occ Health Psych. 1996;1(2):145. https://doi.org/10.1037/1076-8998.1.2.145

67. Moore S, Grunberg L, Greenberg E. Repeated downsizing contact: the effects of similar and dissimilar layoff experiences on work and well-being outcomes. Journ of Occu Health Psych. 2004;9(3):247. https://doi.org/10.1037/10768998.9.3.247

68. Kalimo R, Taris TW, Schaufeli WB. The effects of past and anticipated future downsizing on survivor well-being: an equity perspective. J Occ Health Psych. 2003;8(2):91.https:// doi.org/10.1037/1076-8998.8.2.91

69. Egan M, Bambra C, Thomas S, Petticrew M, Whitehead M, Thomson H. The psychosocial and health effects of workplace reorganisation. 1. A systematic review of organisational-level interventions that aim to increase employee control. J Epi Com Health. 2007;61(11):945-54. https://doi.org/10.1136/ jech.2006.054965

70. Brenner MH, Andreeva E, Theorell T, Goldberg M, Westerlund $\mathrm{H}$, Leineweber $\mathrm{C}$, et al. Organizational downsizing and depressive symptoms in the European recession: The experience of workers in France, Hungary, Sweden and the United Kingdom. PLOS one. 2014;9(5):e97063. https://doi. org/10.1371/journal.pone.0097063

71. Grunberg L, Moore SY, Greenberg E. Differences in psychological and physical health among layoff survivors: The effect of layoff contact. J Occ Health Psyc. 2001;6(1):15. https://doi.org/10.1037/1076-8998.6.1.15

72. Probst TM. Exploring employee outcomes of organizational restructuring: A Solomon four-group study. Group Org Managem. 2003;28(3):416-39. https://doi. org/10.1177/1059601102250825

73. Dahl MS. Organizational change and employee stress. Managem Sci. 2011;57(2):240-56. https://doi.org/10.1287/ mnsc. 1100.1273

74. Wagstaff CR, Gilmore S, Thelwell RC. When the show must go on: Investigating repeated organizational change in elite sport. J Change Managem. 2016;16(1):38-54. https://doi.org/ $10.1080 / 14697017.2015 .1062793$
75. Eisen EA, Picciotto S, Robins JM. Healthy worker effect Encyclopedia of environmetrics. 2006;3.

76. Nergaard K. Tilknytningsformer i norsk arbeidsliv. Nullpunktsanalyse. Fafo-report; 2016.

77. Virtanen M, Kivimäki M, Joensuu M, Virtanen P, Elovainio M, Vahtera J. Temporary employment and health: a review. Int J Epidem. 2005;34(3):610-22. https://doi.org/10.1093/ije/ dyi024

78. Aronsson G, Gustafsson K, Dallner M. Work environment and health in different types of temporary jobs. Eur J Work Org Psych. 2002;11(2):151-75. https://doi. org/10.1080/13594320143000898

79. Virtanen P, Janlert U, Hammarström A. Exposure to temporary employment and job insecurity: a longitudinal study of the health effects. Occ Environ Med. 2011;68(8):570-4. https:// doi.org/10.1136/oem.2010.054890

80. Virtanen P, Saloniemi A, Vahtera J, Kivimaäki M, Virtanen M, Koskenvuo M. The working conditions and health of nonpermanent employees: are there differences between private and public labour markets? Econ Indust Democrac. 2006;27(1):3965. https://doi.org/10.1177/0143831X06061072

81. Moorman RH, Podsakoff PM. A meta-analytic review and empirical test of the potential confounding effects of social desirability response sets in organizational behaviour research. J Occ Org 1 Psych. 1992;65(2):131-49. https://doi. $\operatorname{org} / 10.1111 / j .2044-8325.1992 . t b 00490 . x$

82. Donaldson SI, Grant-Vallone EJ. Understanding self-report bias in organizational behavior research. J Business Psych. 2002;17(2):245-60. https://doi. org/10.1023/A:1019637632584

83. Bonde JPE. Psychosocial factors at work and risk of depression: a systematic review of the epidemiological evidence. Occ Environ Med. 2008;65(7):438-45. https://doi. org/10.1136/oem.2007.038430

84. Schmidt S, Roesler U, Kusserow T, Rau R. Uncertainty in the workplace: Examining role ambiguity and role conflict, and their link to depression-a meta-analysis. Eur J Work Org Psych. 2014;23(1):91-106. https://doi. org/10.1080/1359432X.2012.711523

85. Viswesvaran C, Sanchez JI, Fisher J. The role of social support in the process of work stress: A meta-analysis. J Vocation Behav. 1999;54(2):314-34. https://doi.org/10.1006/ jvbe.1998.1661

86. Jackson TA, Meyer JP, Wang X-H. Leadership, commitment, and culture: A meta-analysis. Journal of Leaders Org Stud. 2013;20(1):84-106. https://doi. org/10.1177/1548051812466919

87. Schyns B, Schilling J. How bad are the effects of bad leaders? A meta-analysis of destructive leadership and its outcomes. Leaders Quart. 2013;24(1):138-58. https://doi.org/10.1016/j. leaqua.2012.09.001

Received for publication: 12 April 2018 